\title{
Clinical efficacy and safety of edaravone therapy in acute cerebral haemorrhage
}

\author{
Meng Yu*, Dao-Pei Zhang, Ya-Fang Ren, Hong-Tao Zhang, Sheng-Qi Fu and \\ Shu-Ling Zhang \\ Neurology Dept.1, Brain Hospital, Zhengzhou People's Hospital, Zhengzhou, 450000, PR China
}

*For correspondence: Email: ymyytjpr@163.com

Received: 12 April 2016

Revised accepted: 24 August 2016

\begin{abstract}
Purpose: To evaluate the clinical efficacy and safety of edaravone in the treatment of acute cerebral haemorrhage $(\mathrm{ACH})$.

Methods: This study recruited 120 patients who developed $\mathrm{ACH}$. The patients were divided into control and treatment groups with 60 patients per group. The control group underwent conventional treatment and the treatment group also received intravenous edaravone. The volumes of cerebral edema and cerebral hematoma, high-sensitivity C-reactive protein (hs-CRP) and interleukin-6 (IL-6) levels, and Chinese Stroke Scale (CSS) score before and after treatment were compared between the two groups. Results: The respective cerebral edema volumes of the control and treatment groups decreased from $20.99 \pm 12.09$ and $21.80 \pm 12.01 \mathrm{~mL}$ on day 0 to $11.23 \pm 6.34$ and $12.11 \pm 5.98 \mathrm{~mL}$ at day 7 and $4.69 \pm$ 4.03 and $4.64 \pm 3.9 \mathrm{~mL}$ on day $14(P<0.05)$. The respective cerebral hematoma volumes of the control and treatment groups decreased from $18.98 \pm 12.04$ and $18.97 \pm 12.07 \mathrm{~mL}$ on day 0 to $12.34 \pm 6.57$ and $11.89 \pm 4.01 \mathrm{~mL}$ at day 7 and $9.49 \pm 3.95$ and $9.52 \pm 3.96 \mathrm{~mL}$ on day 14. Compared with pretreatment, hs-CRP and IL-6 levels and CSS score of the two groups decreased significantly following treatment $(p<0.05)$; the differences in the cerebral edema and hematoma volumes of the two groups on days 7 and 14 were not significant $(p>0.05)$. The hs-CRP and IL-6 levels and CSS scores of the treatment group decreased appreciably $(p<0.05)$, while the incidence of adverse reactions in the treatment and control groups was 16.67 and $13.33 \%$, respectively, but the difference was not significant $(p>0.05)$.

Conclusion: Edaravone shows remarkable clinical efficacy and safety with no obvious adverse reactions in the treatment of $A C H$. Therefore, its use is recommended.
\end{abstract}

Keywords: Cerebral haemorrhage, Edaravone, Cerebral edema, C-reactive protein, Interleukin-6, Chinese Stroke Scale

Tropical Journal of Pharmaceutical Research is indexed by Science Citation Index (SciSearch), Scopus, International Pharmaceutical Abstract, Chemical Abstracts, Embase, Index Copernicus, EBSCO, African Index Medicus, JournalSeek, Journal Citation Reports/Science Edition, Directory of Open Access Journals (DOAJ), African Journal Online, Bioline International, Open-J-Gate and Pharmacy Abstracts

\section{INTRODUCTION}

Cerebral haemorrhage $(\mathrm{CH})$ or encephalorrhagia is a form of "stroke" and is a common serious brain complication occurring in elderly patients with hypertension [1,2]. CH [3,4] refers to haemorrhage caused by the rupture of blood vessels in the non-traumatised brain parenchyma, and its most common causes include hypertension, cerebral arteriosclerosis, and intracranial vascular malformations. Because it is usually induced by force, agitation, and other factors, most cases occur during activity. $\mathrm{CH}$, which usually happens suddenly [5], manifests as altered consciousness, limb paralysis, aphasia, and other neurological forms of 
damage. Characterised by its rapid incidence, critical condition, and high mortality rate, it can seriously affect patient health. Oxygen free radicals (OFRs) play an important role in cerebral edema and secondary cerebral injury. The compressive and stimulatory effect of a hematoma on brain tissues caused by acute cerebral haemorrhage $(\mathrm{ACH})$ increase the production of OFRs, which aggravates cerebral ischemia and hypoxia $[6,7]$.

Edaravone [8] is a new free radical scavenger with good lipophilicity that has $60 \%$ permeability across the blood-brain barrier. It can scavenge free radicals, reduce the oxidative damage caused by polyunsaturated fatty acids, which are components of the cell phospholipid membrane, and inhibit neuronal apoptosis and cell peroxidation after a haemorrhage, relieving cerebral edema and cerebral tissue impairment.

Currently, edaravone is widely used in the early treatment of patients with acute cerebral infarction and its remarkable neuroprotective effect has been recognised [9]. Consequently, this study examined its use for the treatment of patients with $\mathrm{ACH}$ and compared its efficacy and safety with those of conventional treatment.

\section{METHODS}

\section{Study setting and design}

This study enrolled 120 cases of $\mathrm{ACH}$ treated at Zhengzhou People's Hospital from February, 2013 to December, 2014. All of the cases of ACH were confirmed using computed tomography (CT) or magnetic resonance imaging (MRI). Patients with systemic disease, haemorrhagic cerebral infarction, cerebral hernia, deep coma, severe complications, dementia, or severe mental disorders were excluded. All of the eligible patients gave informed consent and the study was approved by the medical ethics committee of Zhengzhou People's Hospital (approval no: ZPH20150408YM) and followed the tenets of the Declaration of Helsinki [10]. The patients were divided into control and treatment groups using a random digital table method, with 60 per group. In the control group (mean age of $65.40 \pm 2.40$ (range $56-76$ ) years; 34 men, 26 women); the average time from onset of $\mathrm{CH}$ to treatment was $0.90 \pm 1.40$ (range $3-36$ ) $\mathrm{h}$; the bleeding site was the basal ganglia region in 20 cases, lobes in 22 cases, and thalamus in 18 cases (the largest oval grey matter nuclei in the diencephalon, distributed on both sides of the third cerebral ventricle); and the bleeding volume averaged $30.20 \pm 2.90$ (range $16-45$ ) $\mathrm{mL}$. In the treatment group (mean age $63.90 \pm 2.60$ (range $55-75$ ) years; 32 men, 28 women) the average time from onset of $\mathrm{CH}$ to treatment was $23.50 \pm$ 1.60 (range $4-39$ ) $h$; the bleeding site was the basal ganglia region in 18 cases, lobes in 26 cases, and thalamus in 16 cases; and the average bleeding volume was $32.10 \pm 2.50$ (range $17-48 \mathrm{~mL}$ ) $\mathrm{mL}$. The two patient groups did not differ statistically $(p<0.05)$; therefore, the results of the two groups were comparable.

\section{Treatment}

Patients in the control group were given symptomatic and supportive treatment such as blood pressure control, intracranial pressure reduction, blood pressure adjustment and infection prevention. In addition, the patients in the treatment group were treated with intravenous edaravone $30 \mathrm{mg}$ in $100 \mathrm{~mL}$ of normal saline, twice per day. Two weeks was considered one course of treatment.

\section{Observation index}

The cerebral edema and hematoma volumes, the levels of high-sensitivity C-reactive protein (hsCRP) and interleukin-6 (IL-6), and Chinese stroke scale (CSS) score were compared at days 7 and 14. The cerebral edema and hematoma volumes were measured using hematoma volume measurement software. The hs-CRP and IL-6 levels were determined in fasting venous blood samples using immunoturbidimetry and a radioimmunoassay, respectively, as per the kit instructions.

\section{Statistical analysis}

SPSS 19.0 was used for data processing. Numeric data were compared using Chi-square test. Data are expressed as mean \pm standard deviation (SD) and t-test was used to analyse differences between group data. Differences were considered statistically significant if $p<$ 0.05 .

\section{RESULTS}

\section{Changes in cerebral edema and hematoma volumes}

Before treatment, the differences in the cerebral edema and hematoma volumes between the two groups were not significant $(p>0.05)$; the cerebral edema and hematoma volumes decreased significantly in both groups 7 and 14 days after treatment, although the differences 
between the control and treatment groups were not significant $(p>0.05)$ (Table 1).

\section{hs-CRP and IL-6 levels, and CSS score}

On days 7 and 14 after treatment, the hs-CRP and IL-6 levels and CSS score were decreased compared with day 0 for both groups $(p>0.05)$, and the reduction in the indices was more remarkable in the treatment group than in the controls $(p<0.05)$ (Table 2$)$.

\section{Adverse reactions}

The incidence of adverse reactions in the control group was $13.33 \%$ and included four cases of diarrhoea, four cases of nausea, and no case of liver or kidney function injury; for the treatment group, the incidence of adverse reactions was $16.67 \%$, including two cases of diarrhoea, six cases of nausea, and two cases of liver and kidney function injury; the difference in the incidence of adverse reactions between the two groups was not significant $(p>0.05)$ (Table 3$)$.

\section{DISCUSSION}

Cerebral haemorrhage is an acute cerebrovascular disease with a high incidence that has a high disability rate and mortality. The increased intracranial pressure after $\mathrm{ACH}$ causes ischemic injury in the brain tissue around the haematoma [11], which accelerates the metabolism of arachidonic acid in brain tissue and induces an increase in free radicals. A severe inflammatory reaction occurs in the damaged area, which induces the generation of large amounts of oxygen radicals and superoxide anion free radicals. The major pathological mechanism of the free radical injury is the induction of lipid peroxidation $[12,13]$. The brain is very sensitive to OFRs because brain tissue contains abundant lipids. A large number of OFRs can damage the lysosomal membrane of brain cells, and various hydrolytic enzymes that are released into the cytoplasm can further injure the nerve cells. The red blood cells in the hematoma release a large amount of haemoglobin after being damaged.

Currently, much attention in the treatment of $\mathrm{ACH}$ has focused on the important role of free radicals in the mechanism of $\mathrm{ACH}$ [14]. The free radical scavenger edaravone is widely used in the treatment of acute cerebral infarction; it inhibits the lipid peroxidation process and affects the expression of apoptosis-related genes by scavenging OFRs in body tissues,

Table 1: Cerebral edema and hematoma volumes of the two groups before and after treatment (mean \pm SD)

\begin{tabular}{lccccc}
\hline Parameter & Time & Control & Treatment & t-value & $P$-value \\
\hline \multirow{2}{*}{ Cerebral edema volume } & Before & $20.99 \pm 12.09$ & $18.98 \pm 12.04$ & 1.228 & 0.220 \\
$(\mathbf{m L})$ & Day 7 & $11.23 \pm 6.34$ & $12.34 \pm 6.57$ & 1.038 & 0.315 \\
& Day 14 & $4.69 \pm 4.03$ & $9.49 \pm 3.95$ & 1.016 & 0.341 \\
Cerebral hematoma volume & Before & $21.80 \pm 12.01$ & $18.97 \pm 12.07$ & 1.327 & 0.231 \\
$(\mathrm{~mL})$ & Day 7 & $12.11 \pm 5.98$ & $11.89 \pm 4.01$ & 1.418 & 0.201 \\
& Day 14 & $4.64 \pm 3.99$ & $9.52 \pm 3.96$ & 1.341 & 0.286 \\
\hline
\end{tabular}

Table 2: The hs-CRP and IL-6 levels and CSS score of two groups before and after treatment (mean \pm SD)

\begin{tabular}{lccccc}
\hline Parameter & Time & Control & Treatment & t-value & $\boldsymbol{P}$-value \\
\hline \multirow{3}{*}{ hs-CRP (mg/L) } & Before & $17.98 \pm 12.04$ & $18.97 \pm 12.07$ & 1.017 & 0.313 \\
& Day 7 & $14.56 \pm 5.21$ & $11.89 \pm 4.01$ & 6.251 & 0.004 \\
& Day 14 & $11.04 \pm 3.83$ & $9.52 \pm 3.96$ & 7.853 & 0.003 \\
IL-6 (pg/L) & Before & $49.81 \pm 15.40$ & $50.34 \pm 15.01$ & 1.516 & 0.122 \\
& Day 7 & $36.66 \pm 13.45$ & $25.67 \pm 12.11$ & 2.261 & 0.028 \\
& Day 14 & $25.71 \pm 11.61$ & $17.78 \pm 7.28$ & 3.534 & 0.001 \\
CSS score (points) & Before & $19.05 \pm 8.98$ & $20.01 \pm 0.07$ & 1.366 & 0.185 \\
& Day 7 & $17.23 \pm 7.17$ & $12.31 \pm 7.24$ & 2.228 & 0.024 \\
& Day 14 & $14.92 \pm 8.22$ & $10.34 \pm 8.19$ & 5.112 & 0.006 \\
\hline
\end{tabular}

Table 3: Incidence of adverse reactions in the two groups after treatment

\begin{tabular}{lccccc}
\hline Group & N & Diarrhoea & Nausea & $\begin{array}{c}\text { Liver and kidney } \\
\text { function injury }\end{array}$ & $\begin{array}{c}\text { Total } \\
\mathbf{N}(\%)\end{array}$ \\
\hline Control & 60 & $4(6.67)$ & $4(6.67)$ & 0 & $8(13.33)$ \\
Treatment & 60 & $2(3.33)$ & $6(10.00)$ & $2(3.33)$ & $10(16.67)$ \\
$\mathbf{X}^{2}$ & & & & 0.9923 & \\
$\boldsymbol{P}$-value & & & & 0.3192 & \\
\hline
\end{tabular}


thereby reducing the further damage caused by active oxygen and promoting the recovery of neurological function. One study [15] reported that administering edaravone in the treatment of $\mathrm{ACH}$ had remarkable clinical effect, without affecting blood coagulation, the platelet aggregation process, or bleeding time. Chen et al. [16] found that treating patients with acute cerebral ischemic stroke with edaravone limited the reduction in local cerebral blood flow around the infarcted region. A rat study [17] demonstrated that the intravenous injection of edaravone in animals undergoing ischemia reperfusion blocked the progress of cerebral edema and cerebral infarction, relieved neural symptoms, and limited delayed neuron death. In our study, the cerebral edema and hematoma volumes were significantly smaller in the control and treatment groups after treatment than before treatment, and the curative effect was better in the treatment group. The difference in the incidence of untoward reactions in the two groups was not significant $(p>0.05)$, which was consistent with the research results mentioned above.

Hs-CPR and IL-6 are both important markers of inflammatory reaction. Edaravone markedly suppresses inflammatory markers and inflammatory factors, including hs-CPR and IL-6, reducing further damage following $\mathrm{ACH}$ [18]. In our study, the hs-CRP and IL-6 levels of the two groups decreased dramatically after treatment $(p$ $<0.05$ ), but the reduction was more remarkable in the treatment group $(p<0.05)$. This indicates that treating $\mathrm{ACH}$ using edaravone in combination with conventional therapy can significantly reduce hs-CRP and IL-6 levels.

\section{Limitations of the study}

No significant difference was observed in the reduction in the volumes of cerebral edema and cerebral hematoma between the two groups, which is inconsistent with previous studies. This may be due to the small sample size used. Studies with a large sample size need to be conducted.

\section{CONCLUSION}

The findings of this study indicate that edaravone combined with conventional therapy is beneficial to the recovery of nerve function and improvement in daily activities when used in the treatment of $\mathrm{ACH}$. During the treatment period, no obvious adverse effects and aggravated disease conditions were seen, which further implies that edaravone is safe and effective in the treatment of $\mathrm{ACH}$.

\section{DECLARATIONS}

\section{Acknowledgement}

The authors sincerely thank all who supported this work.

\section{Conflict of Interest}

No conflict of interest associated with this work.

\section{Contribution of Authors}

The authors declare that this work was done by the authors named in this article and all liabilities pertaining to claims relating to the content of this article will be borne by them.

\section{REFERENCES}

1. Ji RY, Li W, Zhang FL, Hao LK. Clinical efficacy of edaravone injection on cerebral hemorrhage. J Apopl Nerv Dis. 2007; 24(3): 356-357.

2. Zhao YC, Wang $T$, Gao YP. Clinical observation of huoxue tongli soup for cerebral hemorrhage. Chin J Trad Chin Med Pharm. 2010; 25(10): 1697-1699.

3. Lu L, Sun XJ, Zhang J, Jiang $Q Q$, Chen JJ. Study of free radical scavenger for the treatment of acute intracerebral hemorrhage. Chin J Crit Care Med. 2007; 27(5): 448-451.

4. Chen JX, Ji YM, Sun SG, Xu F. Effect of edaravone on cell apoptosis and expression of Bcl-2 and Bax protein following intracerebral hemorrhage in rates. J Huazhong Univ Sci Technol (Health Sci). 2007; 36(2): 259-261.

5. Satoh K, Ikeda $Y$, Shioda S, Tobe T, Yoshikawa $T$. Edaravone scavengers nitric oxide. Redox Rep. 2002; 7(4): 219-222.

6. Demerlé-Pallardy C, Gillard-Roubert V, Marin JG, Auguet $M$, Chabrier PE. In vitro antioxidant neuroprotective activity of BN 80933, a dual inhibitor of neuronal nitric oxide synthase and lipid peroxidation. I Neurochem. 2000; 74(5): 2079-2086.

7. Peeling J, Yan HJ, Chen SG, Campbell M, Bigio MRD. Protective effects of free radical inhibitors in intracerebral hemorrhage in rat. Brain Res. 1998; 795(12): 63-70.

8. Tanaka M. Pharmacological and clinical profile of the free radical scavenger edaravone as a neuroprotective agent. Folia Pharmacol Japon. 2002; 119(5): 301-308.

9. Jia J. Clinical observation of edaravone on the treatment of cerebral hemorrhage in 70 patients. Chin Mod Doctor. 2009; 47(24): 123-124.

10. Declaration of Helsinki. The 59th World Medical Conference, 2008.

11. Zhang XF, Mu CP, Cao W. Comparison of anesthesia effect between propofol and midazolam in operations of acute cerebral hemorrhage. J Hainan Med College. 2013; 19(2): 253-255.

Trop J Pharm Res, September 2016; 15(9): 2032 
12. GuXH, Zhang YC, Wu SQ, Ye JT, Wu HQ, Li JD. Clinical analysis of minimally invasive surgery and non-surgical treatment in hypertensive cerebral hemorrhage. Chin Med Herald. 2010; 7(16): 231-232.

13. Du CC, Yan J. Application of nimodipine in the treatment of acute hypertensive intracerebral hemorrhage. Clin Med. 2010; 30(2): 45-46.

14. Maira G, Anile C, Colosimo C, Rossi GF. Surgical treatment of primary supratentorial intracerebral hemorrhage in stuporous and comatose patients. Neurol Res. 2002; 24(1): 54-60.

15. Kong QZ, Chen GC, Lin JZ, Yuan RM, Chen XF. Effect of Xingnaojing Injections Combined with Edaravone in the
Treatment of Acute Cerebral Hemorrhage. Chin Pharmac. 2014; 17(11): 90-91.

16. Chen L, Liu Y, Dong L, Chu X. Edaravone protects human peripheral blood lymphocytes from gammairradiation-induced apoptosis and DNA damage. Cell Stress Chaper. 2015; 20: 289-295.

17. Yuan $Y$, Zha $H$, Rangarajan $P$, Ling EA, Wu C. Antiinflammatory effects of Edaravone and Scutellarin in activated microglia in experimentally induced ischemia injury in rats and in BV-2 microglia. BMC Neurosci. 2014; 15: 125.

18. Brouwers H, Goldstein JN. Therapeutic strategies in acute intracerebral hemorrhage. Neurotherapeutics. 2012; 9(1): 87-98. 